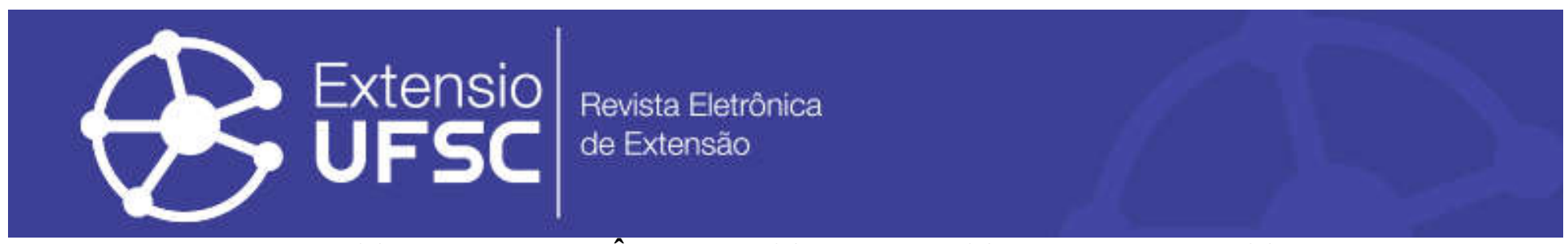

\title{
RELATO DE EXPERIÊNCIA EXTENSIONISTA: EQUIPAMENTOS DE PROTEÇÃO INDIVIDUAL PARA OS EDUCANDOS DO CAMPO
}

\author{
Mateus Torres Miranda \\ Universidade do Estado de Minas Gerais \\ mateus.2137687@discente.uemg.br \\ Mônica Elena Bortolotti da Silva \\ Universidade do Estado de Minas Gerais \\ monica.2197564@discente.uemg.br \\ Franciane Diniz Cogo \\ Universidade do Estado de Minas Gerais \\ franciane.diniz@uemg.br
}

\begin{abstract}
Resumo
Objetivo: relatar a experiência extensionista vivenciada pelo "Projeto "Equipamento de Proteção Individual: sua saúde depende de sua segurança no trabalho". Método: As atividades foram realizadas em escolas públicas e rurais no mês de agosto de 2019, em Passos, Minas Gerais. Foram assistidos os educandos do ensino fundamental e médio. A ação envolveu: palestra interativa e exposição dos equipamentos de proteção individuais (EPI’S) utilizados na agricultura e distribuição de folders. Resultados: a ação de extensão obteve sucesso; foi constatado que se criou uma vertente social e interdisciplinar e a utilização de palestras interativas e exposição dos EPI'S e folders são ferramentas essenciais para orientar e despertar os educandos do campo. Conclusão: o presente projeto de extensão universitária é um elo permanente entre a instituição de ensino superior e a comunidade e apresenta ampla importância interdisciplinar, educativa, cultural, social, científica e política para a graduação em Agronomia.
\end{abstract}

Palavras-chave: Bem Estar. Seguranças. Sustentabilidade Agrícola.

\section{EXTENSIONIST EXPERIENCE STORY: INDIVIDUAL PROTEÇÃO EQUIPMENT FOR OS EDUCANDOS DO CAMPO}

\begin{abstract}
Objective: To report on an extensive experience of the "Personal Protective Equipment Project: Your Health Depends on Your Safety at Work". Method: As activities were performed in public and rural schools in August 2019, in Passos, Minas Gerais. They were assisted by elementary and high school students. The action involved: interactive lecture and exhibition of personal protective equipment (PPE), used in agriculture and distribution of pastes. Results: A successful extension action selected; It was found that it created a social and interdisciplinary aspect and the use of interactive lectures and exposure of PPE and folders are essential tools to guide and awaken the students of the field. Conclusion: the present university extension project is a permanent element between the higher education institution and the community and has wide important interdisciplinary, educational, cultural, social, scientific and scientific importance for undergraduate agronomy.
\end{abstract}

Keywords: Welfare. Security Guards. Agricultural Sustainability.

\section{INFORME DE EXPERIENCIA EXTENSIONAL: EQUIPO DE PROTECCIÓN PERSONAL PARA EDUCADOS DE CAMPO}

\section{Resumen}

Objetivo: Informar sobre la experiencia de extensión del "Proyecto de equipo de protección personal: su salud depende de su seguridad en el trabajo". Método: Las actividades se llevaron a cabo en escuelas públicas y rurales en agosto de 2019, en Passos, Minas Gerais. Estudiantes de primaria y secundaria fueron asistidos. La acción involucrada: conferencia interactiva y exhibición de equipo de protección personal (PPE) utilizado en agricultura y distribución de carpetas. Resultados: la acción de extensión fue exitosa; Se descubrió que se creó un aspecto social e interdisciplinario y el uso de conferencias interactivas y la exposición de EPI'S y carpetas son herramientas esenciales para guiar y despertar a los Estudiantes del campo. Conclusión: el presente proyecto de extensión universitaria es un vínculo permanente entre la institución de educación superior y la comunidad y tiene una gran importância interdisciplinaria, educativa, cultural, social, científica y política para la agronomía de pregrado.

Palavras clave: Bienestar. Seguridad. Sostenibilidad Agrícola. 
Relato de experiência extensionista: equipamentos de proteção individual para os educandos do campo

\section{INTRODUÇÃO}

O Brasil é um país agrícola que visa aumentar a produção sem aumentar a área de plantio, por inovações tecnológicas como sementes geneticamente modificadas e utilização de produtos fitossanitários. De acordo com a Abrasco (2012), o Brasil está entre os maiores consumidores mundiais de agrotóxicos e os educandos do campo convivem diariamente com essa realidade. Neste contexto, destaca-se a importância do uso dos EPI (Equipamento de Proteção Individual), para que os trabalhadores realizem as atividades de maneira segura (FIGUEIREDO; HENRIQUES, 2017), o que justifica a escolha deste tema.

A extensão universitária promove ações no sentido de difundir e ampliar as atividades extramuros da universidade, sendo assim, um processo interdisciplinar, educativo, cultural, social científico e político, que, sob o princípio da indissociabilidade, permite a interação transformadora entre a universidade e a comunidade (FERNANDES et al., 2012).

Neste contexto, é indispensável o alargamento de atuações para toda comunidade, de modo especial a campestre, de modo a serem edificados novos conhecimentos por meio da abertura entre universidade e comunidade, permitindo, assim, o envolvimento dos estudantes de graduação com questões sociais, com a premissa de que a sustentabilidade rural e a redução do êxodo rural podem ser modificadas pela Educação do Campo. Todas as ações de promoções devem ser realizadas de modo que as visões de mundo sejam respeitadas (SIQUEIRA et al., 2017).

Deste modo, as atividades extensionistas devem estar inseridas na comunidade, promovendo recíproca troca de experiências, permitindo a inserção dos estudantes nas ações de impacto social. As vivências contribuíram para a formação desses estudantes como cidadãos que se preocupam com a sociedade. E, assim, por meio dos projetos de extensão universitária, podem ser criadas condições para que o ser humano atue de forma ativa em sua história, na sociedade e seja capaz de transformar a realidade (FREIRE, 1982).

O projeto de extensão universitária da Universidade do Estado de Minas Gerais (UEMG), vinculadoao Curso de Engenharia Agronômica, procura atender as comunidades rurais, em especial as escolas públicas, em Passos, sudoeste de Minas Gerais. O presente trabalho tema como objetivo relatar a experiência extensionista vivenciada pelo projeto "Equipamento de Proteção Individual: sua saúde depende de sua segurança no trabalho". 
Relato de experiência extensionista: equipamentos de proteção individual para os educandos do campo

\section{MATERIAIS E MÉTODOS}

O referido projetode extensão foi executado em trêsescolas da zona-rural, conforme apresentado no Quadro 01, localizadas no município de Passos-MG. Foram assistidos os educandos do ensino fundamental e médio. As atividades foram realizadas em agosto de 2019.

\begin{tabular}{|l|l|}
\hline \multicolumn{1}{|c|}{ Escolas } & \multicolumn{1}{c|}{ Endereço } \\
\hline Escola Municipal Geralda Cândida de Oliveira & Fazenda Boa Vista \\
\hline Escola Municipal Doutor Manoel Patti & Fazenda Mumbuca \\
\hline Escola Municipal Azarias de Melo & Fazenda Cascata \\
\hline \hline
\end{tabular}

Quadro 01 - Escolas rurais do município de Passos - MG. Fonte: Dados desta pesquisa (2019).

As atividades foram desenvolvidas por acadêmicos do Curso de Engenharia Agronômica, com o suporte de bolsas aprovado pelo Programa Institucional de Apoio à Extensão (PAEx), da Universidade do Estado de Minas Gerais (UEMG), em 2019. A atividade foi supervisionada por uma professora orientadora.

As atividades realizadas nas escolas rurais foram: palestra interativa e exposição do EPI'S utilizados na agricultura. Também foi distribuído um folder com os principais equipamentos utilizados para segurança e saúde no campo. Essas atividades visaram simultaneamente envolver o educando, a família e a comunidade, e, assim, promover a valorização da segurança e da saúde do meio rural, assim como a aprendizagem, aumentando, dessa forma, o nível de interesse dos alunos com as questões envolvendo a saúde no trabalho.

A palestra interativa teve início com uma dinâmica para apresentação dos alunos, na sequência foramapresentados os conceitos sobre a NR-31 (Segurança e Saúde no Trabalho na Agricultura, Pecuária Silvicultura, Exploração Florestal e Aquicultura). Essa Norma Regulamentadora tem por objetivo estabelecer os preceitos a serem observados na organização e no ambiente de trabalho, como treinamento em segurança e saúde no trabalho. Também foi exposta a importância em se utilizar os EPIs,e os sintomas apresentados quando utilizados de forma incorreta, como, por exemplo, quando o protetor facial de segurança para proteção da facenão é usado, aumentando o risco de que respingos de produtos químicos se depositem na face. A exposição dos equipamentos foi realizada com o objetivo de envolver os alunos, fazendo com que se tornem sujeitos da troca de informações. 
Relato de experiência extensionista: equipamentos de proteção individual para os educandos do campo

Todas as atividades realizadas com os educandos do campo apresentam as propostas que estão no quadro 2.

\begin{tabular}{|l|}
\hline \multicolumn{1}{|c|}{ Propostas das atividades de extensão universitárias. } \\
\hline Conscientizar os educandos do campo quanto à necessidade da utilização dos Equipamentos \\
de Proteção Individual; \\
\hline Apresentar as formas de utilização dos equipamentos, quais são os danos causados a quem \\
não usa ou faz o uso incorreto dos mesmos; \\
Proporcionar alternativas que esclareçam a importância do EPI, modo de usar, cuidados a \\
serem tomados com os equipamentos antes e após sua utilização, e danos causados à saúde \\
de quem não os utiliza.
\end{tabular}

Quadro 02 - Propostas das atividades realizadas nas Escolas rurais da cidade de Passos - MG. Fonte: Dados desta pesquisa (2019).

Foram quantificados os números de participantes em cada escola, gênero e as séries. Para tanto, utilizou-se a planilha eletrônica Excel.

\section{RESULTADOS E ANÁLISES}

O total de Educandos do Campo participantes chegou a 404, sendo 224 meninos e 180 meninas, distribuídos da educação infantil até o ensino médio, conforme apresentado no quadro 3. O número de estudantespresentes é considerado representativo, uma vez que se tornam disseminadores das informações para a comunidade rural.

As atividades realizadas apresentaram alcances variados, tendo em vista as diferentes idades do público (Quadro 1). Contudo, a utilização de palestras interativas, exposição dos EPI e a distribuição dos folders foram ferramentas essenciais para orientar e despertar os educandos do campo para construir uma sociedade consciente, considerando-se que o Brasil é um dos maiores consumidores mundial de agrotóxicos (ABRASCO, 2012), logo, a utilização de defensivos agrícolas faz parte da rotina da maioria dos educandos em suas propriedades agrícolas.

O levantamento do gênero dos educandos demonstra que 55,5\% são masculinos e 44,5\% femininos, uma diferença de 11\%, portanto. Considerando-se o contexto do campo, onde meninos ainda são a maioria dos que permanecem, e a sociedade é ainda muito patriarcal, os novos conceitos de segurança e bem-estar social podem ser inseridos gradualmente nas rotinas agrícolas. 
Relato de experiência extensionista: equipamentos de proteção individual para os educandos do campo

As dinâmicas utilizadas nas palestras interativas foram realizadas de maneira lúdica para os educandos da educação infantil e primeiros anos do ensino fundamental e de modo informativo, para os anos finais e colegial.

\begin{tabular}{|c|c|c|}
\hline Série Escolas / Gênero & Masculino & Feminino \\
\hline \multicolumn{3}{|c|}{................................Escola Municipal Geralda Cândida de Oliveira.......................... } \\
\hline Educação Infantil - 04 anos & 04 & 03 \\
\hline Educação Infantil - 05 anos & 08 & 05 \\
\hline $1^{\circ}$ ano & 06 & 08 \\
\hline $2^{\circ}$ ano & 09 & 08 \\
\hline $3^{\circ}$ ano & 03 & 05 \\
\hline $4^{\circ}$ ano & 05 & 04 \\
\hline $5^{\circ}$ ano & 09 & 08 \\
\hline $6^{\circ}$ ano & 13 & 08 \\
\hline $7^{\circ}$ ano & 11 & 08 \\
\hline $8^{\circ}$ ano & 07 & 05 \\
\hline $9^{\circ}$ ano & 08 & 04 \\
\hline Total & 83 & 66 \\
\hline \multicolumn{3}{|c|}{ 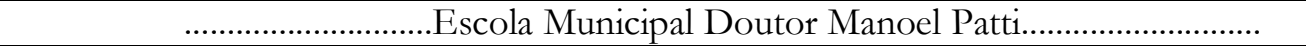 } \\
\hline $5^{\circ}$ ano & 11 & 05 \\
\hline $6^{\circ}$ ano & 09 & 10 \\
\hline $7^{\circ}$ ano & 08 & 07 \\
\hline $8^{\circ}$ ano & 06 & 03 \\
\hline $9^{\circ}$ ano & 07 & 06 \\
\hline $1^{\circ}$ colegial & 15 & 07 \\
\hline $2^{\circ}$ colegial & 07 & 00 \\
\hline $3^{\circ}$ colegial & 05 & 05 \\
\hline Total & 68 & 43 \\
\hline \multicolumn{3}{|c|}{ 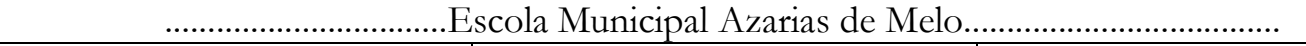 } \\
\hline Pré de 04 anos & 06 & 03 \\
\hline Pré de 05 anos & 05 & 07 \\
\hline $1^{\circ}$ série & 14 & 07 \\
\hline $2^{\circ}$ série & 09 & 06 \\
\hline $3^{\circ}$ série & 06 & 09 \\
\hline $4^{\circ}$ série & 01 & 02 \\
\hline $5^{\circ}$ ano & 06 & 06 \\
\hline $6^{\circ}$ ano & 04 & 10 \\
\hline $7^{\circ}$ ano & 03 & 10 \\
\hline $8^{\circ}$ ano & 11 & 07 \\
\hline $9^{\circ}$ ano & 08 & 04 \\
\hline Total & 73 & 71 \\
\hline Total Geral & 224 & 180 \\
\hline $\begin{array}{l}\text { Total de educandos } \\
\text { participantes }\end{array}$ & \multicolumn{2}{|c|}{404} \\
\hline
\end{tabular}


Relato de experiência extensionista: equipamentos de proteção individual para os educandos do campo

Quadro 03-Número de alunos que participaram do projeto de extensão "Equipamento de Proteção Individual: sua saúde depende de sua segurança no trabalho”. Fonte: Dados desta pesquisa (2019).

O estudante de Engenharia Agronômica tem por objetivo compartilhar seus conhecimentos adquiridos no decorrer do curso de graduação. Esse compartilhamento é de grande relevância, uma vez que o Brasil está entre os maiores consumidores mundiais de agrotóxicos e os educandos do campo (ABRASCO, 2012) convivem diariamente com essa realidade.

O Projeto de Extensão sobre uso correto de EPI'S apresenta uma relação direta com o mercado de trabalho, o que permite aos educandos do campo, futuros proprietários, trabalhadores rurais e/ou profissionais da assistência técnica conscientizarem-se da precisão dos EPI'S, uma vez que seu uso está relacionado com a saúde pública e bem-estar. O uso dos EPI'S é necessário para que os trabalhadores realizem as atividades de maneira segura (FIGUEIREDO; HENRIQUES, 2017).

Durante as atividades, foi demonstrado e dito que EPI é todo dispositivo ou produto utilizado pelo trabalhador, para a proteção dele contra riscos capazes de ameaçar sua segurança e saúde durante as atividades. Os participantes foram orientados ainda utilizar corretamente os EPI'S no campo, onde a proteção que proporcionam é fundamental para que sejam reduzidos os níveis de intoxicação causados pelo uso inadequado dos equipamentos (FIGUEIREDO; HENRIQUES, 2017). No decorrer das ações, foi possível perceber que o tema EPI não era desconhecido pela plateia de diferentes idades, no entanto, várias dúvidas foram surgindo quanto à utilização correta do EPI, e quais devem ser utilizados em cada situação, como, por exemplo, qual a sequência correta para se colocar e tirar o EPI. Tais situações sinalizam a relevância deste projeto.

Na Imagem 1, é demonstrado o desenvolvimento da exposição interativa dos palestrantes (estudantes do curso de Engenharia Agronômica) que apresentam o conjunto de EPI'S, e, em seguida, a maneira correta de utilizá-los. Os educandos do campo colocaram-se à disposição para serem chamados a aprender a colocar e tirar o EPI, o que evidenciou a boa participação do público. 
Relato de experiência extensionista: equipamentos de proteção individual para os educandos do campo

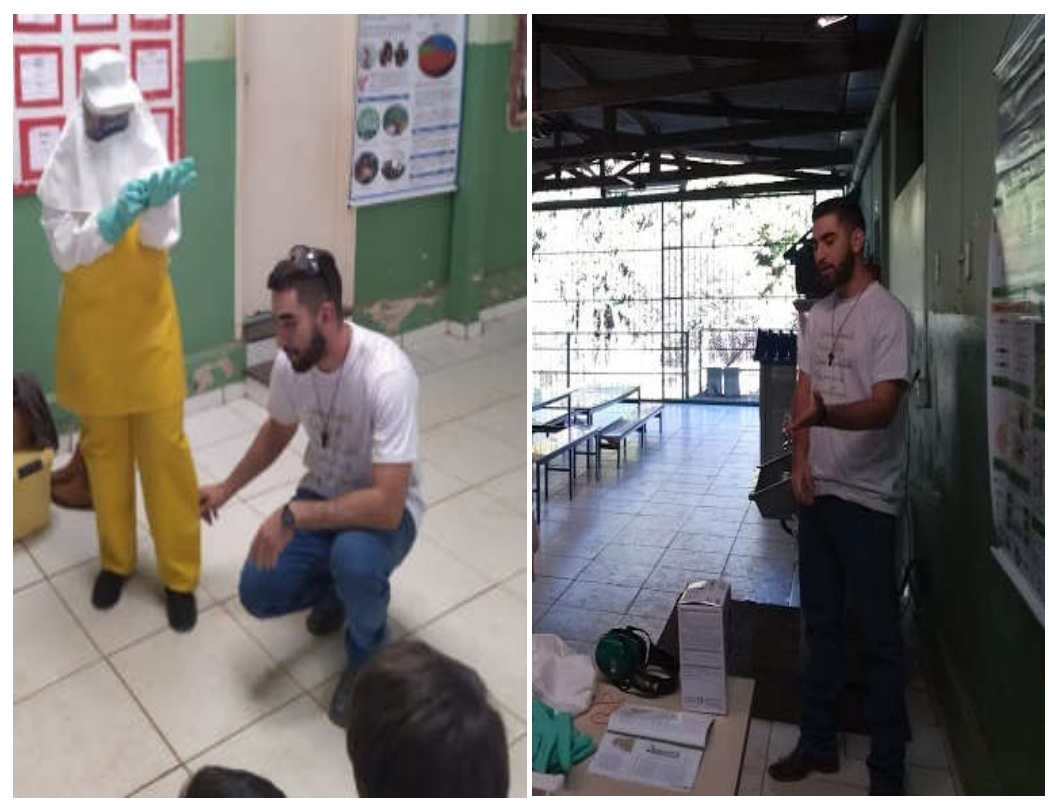

Imagem 1 -Exposição interativacom os Educandos do Campo, demonstração dos EPI'S e a sua utilização correta.

Fonte: Dados deste projeto de extensão (2019)

Nesse contexto, foi verificado que, apesar das normas regulamentadoras ainda falta conscientização por parte da população rural quanto à importância de utilização dos equipamentos. Essa é uma orientação que pode ser realizada com a participação dos educandos do campo, para que atinjam a maturidade cientes da necessidade da utilização de EPI'S. Trata-se de uma questão de saúde pública.

Para os educandos acima de 10 anos, foi abordada a Portaria $n^{\circ}$ 86, do Ministério do Trabalho e do Emprego, de 3 de março de 2005, publicada no Diário Oficial da União (D.O.U) em 4 de março de 2005, que aprovou a Norma Regulamentadora de Segurança e Saúde no Trabalho, na Agricultura, Pecuária, Silvicultura, Exploração Florestal e Aquicultura, a Norma Regulamentadora $\mathrm{n}^{\circ} 31$ (BRASIL, 2005).

A Norma Regulamentadora n 31 (NR-31), tem por objetivo:

Estabelecer os preceitos a serem observados na organização e no ambiente de trabalho, de forma a tornar compatível o planejamento e o desenvolvimento das atividades da agricultura, pecuária, silvicultura, exploração florestal e aquicultura com a segurança e saúde e meio ambiente do trabalho (BRASIL, 2005). 
Relato de experiência extensionista: equipamentos de proteção individual para os educandos do campo

A ação deste projeto de extensão também tratou da formação de recursos humanos quando apresentou informações a classificação toxicológica (Quadro 4) e pictogramas, bem como o modo de interpretá-los a partir da leitura do rótulo/bula do produto. Os rótulos das embalagens de agrotóxicos trazem informações sobre o grupo químico, ingrediente ativo e informações dos produtos, a fim de evitar intoxicações e orientar o uso de EPI'S. Ênfase especial foi dada a esta questão, tendo em vista que é comum os agricultoresaplicarem defensivos sem EPI, o que leva a consequentes intoxicações (ARAÚJO et al., 2000).

\begin{tabular}{|l|l|l|}
\hline Classe & Cor de faixa & Nível de toxicidade \\
\hline I & Vermelha & Extremamente tóxico \\
\hline II & Amarela & Altamente tóxico \\
\hline III & Azul & Medianamente tóxico \\
\hline IV & Verde & Pouco tóxico \\
\hline
\end{tabular}

Quadro 04- Classificação toxicológica: classe, cor de faixa e nível de toxicidade dos defensivos agrícolas.

O diálogo com os estudantes do campo no decorrer das atividades permitiu verificar, por meio de suas falas, que existem EPI'S nas propriedades rurais, pois eles conheciam os equipamentos apresentados, como luvas, viseira, botas de borracha. No entanto, muitos relatam que nem sempre eram utilizados, ocorrendo até mesmo relatos de casos de intoxicação por defensivos. Tais situações permitiram a melhor comunicação e a conscientização dos educandos da importânciado uso correto dos EPI.

Em relação às atividades que não geraram os resultados esperados, os participantes tiveram dificuldade em entender as normas regulamentadoras. Sendo assim, para futuras gerações, atividades relacionadas a esta parte devem ser entregues em impressos, pois assim é possível levar o material para casa, onde as informações podem ser completadas por buscas na internet, não caindo no esquecimento.

Os professores e educandos das escolas rurais (Quadro 1) foram muito receptivos ao projeto de extensão "Projeto "Equipamento de Proteção Individual: sua saúde depende de sua segurança no trabalbo" e se mostraram muito interessados no assunto, perguntando quando seria a próxima visita.

Ao término da atividade, o grupo de estudantes extensionistas refletiu sobre a vivência nas comunidades rurais com a professora orientadora do projeto de extensão e considerou essa uma ação de sucesso. Os elementos que levaram a essa interpretação foram as interações e 
Relato de experiência extensionista: equipamentos de proteção individual para os educandos do campo

partilhas dos educandos do campo durante as atividades, por se tratar de um tema que se aproxima de suas realidades rurais.

Nesta proposta, os alunos de graduação foram desafiados a montar o banner, folders, e a se comunicarem com os alunos do ensino fundamental e do ensino médio das escolas públicas rurais, de maneira a impulsionarem-nos a favor da importância do uso de EPI'S nas atividades rurais. Os estudantes de agronomia participantes tiveram, assim, a oportunidade de realizar atividades extensionistas de impacto social, despertando o seu papel junto à comunidade.

Por fim, esta ação de extensão universitária se conclui com o compartilhamento de conhecimento com a comunidade científica, através deste relato de experiência, tendo em vista que sua divulgação possa motivar outros estudantes e professores a incorporar a extensão universitária no processo de ensino-aprendizagem, tornando cada vezmais fortes os pilares ensino, pesquisa e extensão.

\section{CONSIDERAÇÕES FINAIS}

Direcionado pelo seu objetivo, ao relatar a experiência extensionista vivenciada pelo projeto "Equipamento de Proteção Individual: sua saúde depende de sua segurança no trabalho", foram obtidas as seguintes conquistas:

a) melhoria das ações extensionistas da UMEG unidade de Passos, na cidade de Passos, junto às comunidades rurais, em especial os educandos do campo, voltadas a esclarecer aspectos sobre o uso correto de EPI’S na agricultura.

b) inserção dos graduandos de Engenharia Agronômica como extensionistas na comunidade rural, para melhoria da formação acadêmica através do partilhamento de conhecimentos adquiridos em sala de aula sobre o uso correto de EPI'S na agricultura.

c) a relevância extramuros da socialização entre universidade e comunidade rural para conscientização dos estudantes quanto à realidade ao seu redor transformando os futuros profissionais da agricultura em pessoas preocupadas com a comunidade rural.

Por fim, conclui-se que a presente ação de extensão rural permitiu a edificação de conhecimentos e entrosamentos através do diálogo com a comunidade externa, bem como a identificação de seus problemas. Desta forma, tem-se com este relato de experiência sobre atividade realizada em prol a educação do campo também o objetivo de contribuir com a redução do êxodo rural, buscando aumentar a permanência no campo. Essa é uma boa maneira 
Relato de experiência extensionista: equipamentos de proteção individual para os educandos do campo

de ofertar à comunidade científica uma reflexãosobre as práticas pedagógicas que envolvem o ensino, a pesquisa e a extensão, para que se torne possível praticar a cidadania.

\section{AGRADECIMENTOS}

Os autores agradecem à bolsa concedida pelo programa PAEx da UEMG. Também agradecem a recepção calorosa da Escola Municipal Geralda Cândida de Oliveira, da Escola Municipal Doutor Manoel Patti e da Escola Municipal Azarias de Melo.

\section{REFERÊNCIAS}

ARAÚJO, A. C. P.; NOGUEIRA, D. P.; AUGUSTO, L. G. S. Impacto dos praguicidas na saúde: estudo da cultura de tomate. Revista de Saúde Pública, São Paulo, v. 34, n. 3, p. 309-313, 2000.

BRASCO - Associação Brasileira de Saúde Coletiva. Dossiê Abrasco. Um alerta sobre os impactos dos agrotóxicos na saúde. Parte 1 - Agrotóxicos Segurança Alimentar e Nutricional e Saúde. Rio de Janeiro, 2012.

BRASIL. Portaria $n^{\circ}$ 86, de 03 de março de 2005. Aprova a Norma Regulamentadora de Segurança e Saúde no Trabalho na Agricultura, Pecuária, Silvicultura, Exploração Florestal e Aquicultura. Ministério do Trabalho e Emprego. Brasília, DF, 2005. D.O.U de 04/03/05. Disponível em: http://www.mma.gov.br/estruturas/pnf/_arquivos/portaria_mte_86_05.pdf. Acesso em: 04 abr. 2019.

FERNANDES, M.C.; SILVA, L.M.S.; MACHADO, A.L.; MOREIRA, T.M. Universidade e a extensão universitária: a visão dos moradores das comunidades circunvizinhas. EducRev (Belo Horizonte), v. 28, n. 4, p. 169-94, 2012.

FIGUEIREDO, A. M. C.; HENRIQUES, A. L. M. A aplicabilidade da norma regulamentadora n. 31 em relação ao uso de agrotóxicos e dos equipamentos de proteção individual (EPIS). Revista do Tribunal Regional do Trabalho da 15ª Região, n. 50, 2017.

FREIRE P. Pedagogia do oprimido. 11a ed. Rio de Janeiro: Paz e Terra; 1982.

SIQUEIRA, S.M.C.; JESUS, V.S.D.; SANTOS, E.M.B.D.; WHITAKER, M.C.O.; SOUSA, B.V.N.; CAMARGO, C.L.D. Atividades extensionistas, promoção da saúde e desenvolvimento sustentável: experiência de um grupo de pesquisa em enfermagem. Escola Anna Nery, v. 21, n. 1, p. 1-7, 2017.

Recebido em: 05/11/2019

Aceito em: 11/12/2020 